\title{
A X-ray Study of $\beta$-Phase and Molecular Orientation in Nucleated and Non-Nucleated Injection Molded Polypropylene Resins
}

\author{
Marcia Maria Favaro, Marcia Cristina Branciforti, Rosario Elida Suman Bretas*
}

\author{
Department of Materials Engineering, Federal University of São Carlos - UFSCar, \\ Rod. Washington Luís, Km 235, 13565-905 São Carlos - SP, Brazil
}

Received: June 9, 2009; Revised: October 8, 2009

\begin{abstract}
The development of $\alpha$ and $\beta$-phases and the molecular orientation of injection molded disks of two isotactic polypropylene (i-PP) resins were studied by wide angle X-ray diffraction (WAXD) and pole figures. A nucleated (NPP) and non-nucleated (HPP) polymers were analyzed. The main proposal of this article was the comprehensive study of the interrelations between the processing conditions, phase contents and PP $\alpha$-phase molecular orientation of injection molded PP resins. In both resins, it was observed that the $\alpha$-phase was present in all regions along the thickness while the $\beta$-phase was present mainly in the external layers, decreasing from the surface to the core; however this last phase was present in a very small amount in the NPP resin. For both polymers, the orientation of the macromolecules c-axis was higher along the flow direction (RD) than along the transverse direction (TD). The b-axis of the PP $\alpha$-phase molecules was oriented to the thickness direction (ND). The orientation of the c-axis along RD and b-axis along ND of the NPP samples was considerably higher than of the HPP samples, due to the NPP faster crystallization kinetics. For both polymers, the most influential processing parameters on the molecular orientation were the mold temperature and flow rate. The results indicate that, as the mold temperature increased, the characteristic molecular orientation of PP $\alpha$-phase, with c-axis along RD and b-axis along ND, decreased. With increase in the flow rate an increase of the c-axis molecular orientation of the samples along RD was observed.
\end{abstract}

Keywords: $X$-ray pole figures, molecular orientation, injection molding, polypropylene, $\beta$-PP

\section{Introduction}

During injection molding, polymer crystallization occurs mainly under shear and elongation rates, but also under quiescent conditions, depending on the flow characteristics. Thus, the developed morphology reflects these flow patterns, and usually is composed of different and characteristic layers along the thickness of the sample ${ }^{1-9}$. In the case of semi crystalline thermoplastics with fast crystallization kinetics, this morphology is known as "skin-core" and is formed by three main zones ${ }^{4-6,10-16}$ :

- Skin: Composed of a frozen layer (developed when the molten polymer reaches the mold walls) and a flow induced layer (developed during the filling stage as a consequence of the supercooling promoted by the frozen layer). In the flow induced layer, the lamellas grow perpendicular to the direction of the filling, with the thickness of the layer being controlled by the cooling rate and tensions imposed to the molten polymer;

- Transition zone: A layer situated between the skin and the core. In this zone an increasing quantity of orientation caused by the shear rates is observed, which produces deformed spherulites in the flow direction; and

- Core: The center layer. A maximum velocity is developed at the center, therefore the shear rates will be zero or very low and the core will present the typical morphology of quiescent conditions.

In the case of i-PP, it is known that when it crystallizes under quiescent conditions three different crystalline structures $(\alpha, \beta$ and $\gamma$ ) will develop. However, in the presence of flow, it is observed ${ }^{12}$ that the i-PP chains orient, creating fibrillar nucleus. It has also be shown ${ }^{1}$ that the quantity of $\beta$ phase in i-PP samples processed in a slit die decrease with the decreasing of the shear rate imposed during the crystallization process;
In the literature ${ }^{17-21}$ was revealed the promising mechanical properties of $\beta$-form in i-PP articles and it was also exposed that when special crystallization procedures are used or, in particular, specific nucleators as N,N'-dicyclohexylnaphthalene-2,6-dicarboxamide and sodium benzoate are added, the $\beta$-form can become as predominant crystalline form in common i-PP articles. Dong and cowokers ${ }^{17}$ demonstrated that the sodium benzoate shows apparently versatile nucleating characteristic on the crystallization behavior of i-PP and that this nucleating activity is highly dependent on processing parameters. However, sodium benzoate is less effective than traditional $\beta$-nucleating agent on inducing $\beta$ - crystal form in i-PP;

In injection molded morphologies a gradient of molecular orientation along the sample thickness is also observed which is related to the deformation rates and temperature gradients. The maximum orientation value is usually obtained in the transition zone, being almost zero in the center of the molded sample, as a result of the shear rates, which are maximum near the wall and zero in the center. This molecular orientation gradient is responsible for the improved properties in the orientation direction; on the other hand, the properties along the perpendicular direction usually are worse $\mathrm{e}^{22-25}$.

The parameters that affect the molecular orientation are: shear and elongation tensions imposed to the molten polymer during their solidification, processing conditions (injection and mold temperatures, packing pressure and flow rate, among others) and intrinsic characteristics of the polymer (relaxation time, crystallization kinetics and chains rigidity, for example ${ }^{22-33}$ ). However, the complete knowledge of the correlation between molecular orientation and processing parameters of injection molded samples is still subject of research. 
Table 1. Properties of the polypropylene resins.

\begin{tabular}{lrr}
\hline & HPP & NPP \\
\hline Melt flow index $\left(230{ }^{\circ} \mathrm{C}\right)(\mathrm{g} / 10 \mathrm{~min})^{(*)}$ & 3.5 & 3.5 \\
Density $\left(23^{\circ} \mathrm{C}\right)\left(\mathrm{g} / \mathrm{cm}^{3}\right){ }^{(*)}$ & 0.905 & 0.905 \\
Weight average molecular weight $\left(\mathrm{M}_{\mathrm{w}}\right)\left(\mathrm{g} \cdot \mathrm{mol}^{-1}\right)^{(*)}$ & 425,200 & 412,900 \\
Molecular weight distribution ${ }^{(*)}\left(\mathrm{M}_{\mathrm{w}} / \mathrm{M}_{\mathrm{n}}\right)$ & 8.4 & 8.7 \\
Melting temperature $\left(\mathrm{T}_{\mathrm{m}}\right)\left({ }^{\circ} \mathrm{C}\right)^{(* *)}$ & 171.4 & 168.9 \\
Crystallization temperature $\left(\mathrm{T}_{c}\right)\left({ }^{\circ} \mathrm{C}\right)^{(* *)}$ & 103.8 & 123.5 \\
\hline
\end{tabular}

*as given by the supplier; **as measured by modulated differential scanning calorimetry (model Q-100 from TA Instruments, $40^{\circ} \mathrm{C} / \mathrm{min}$ ).

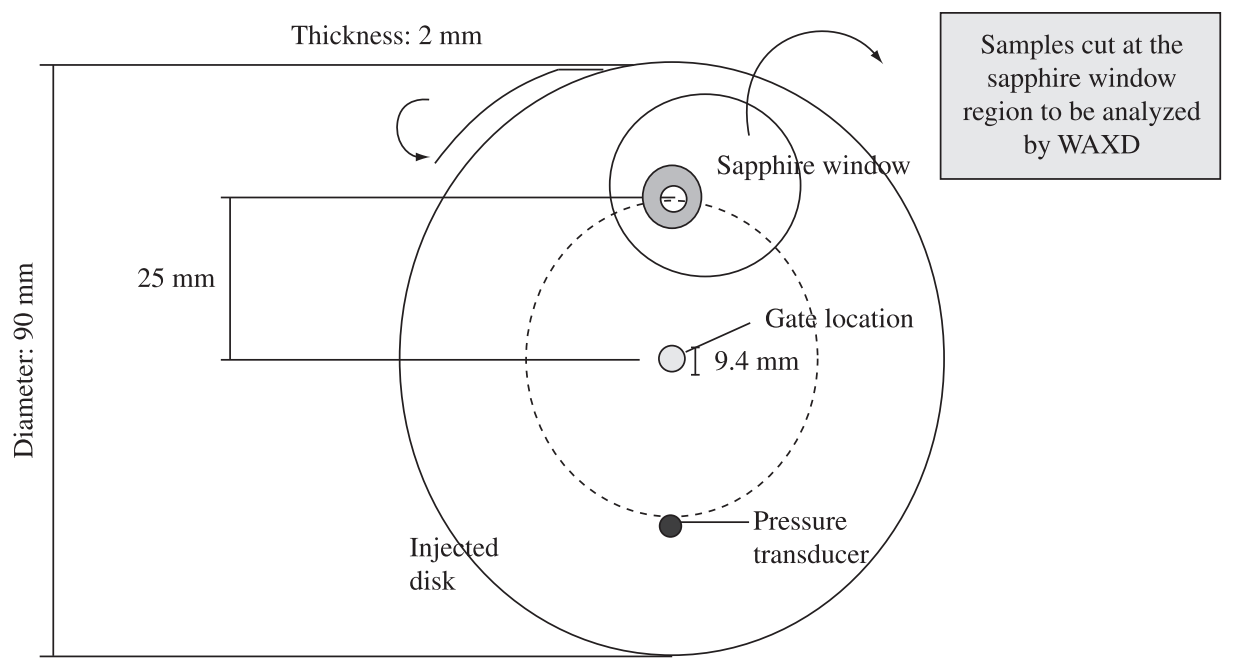

(a)

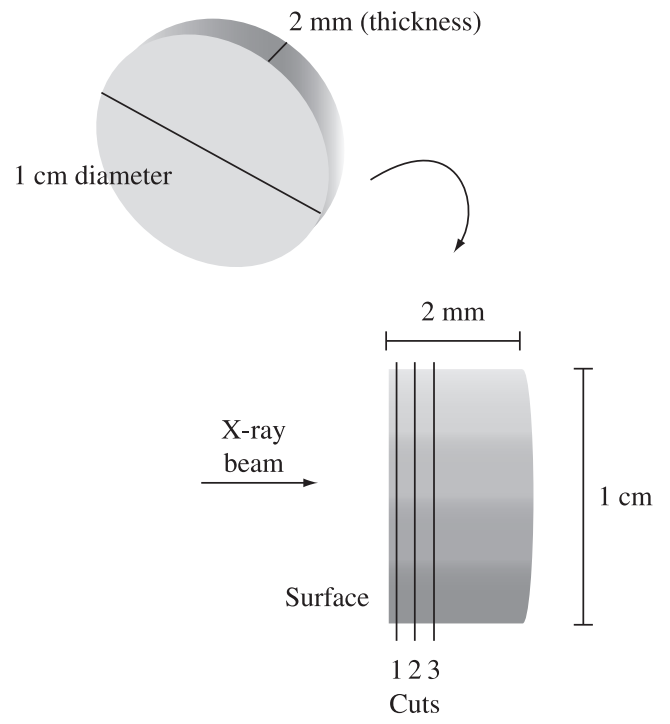

(b)

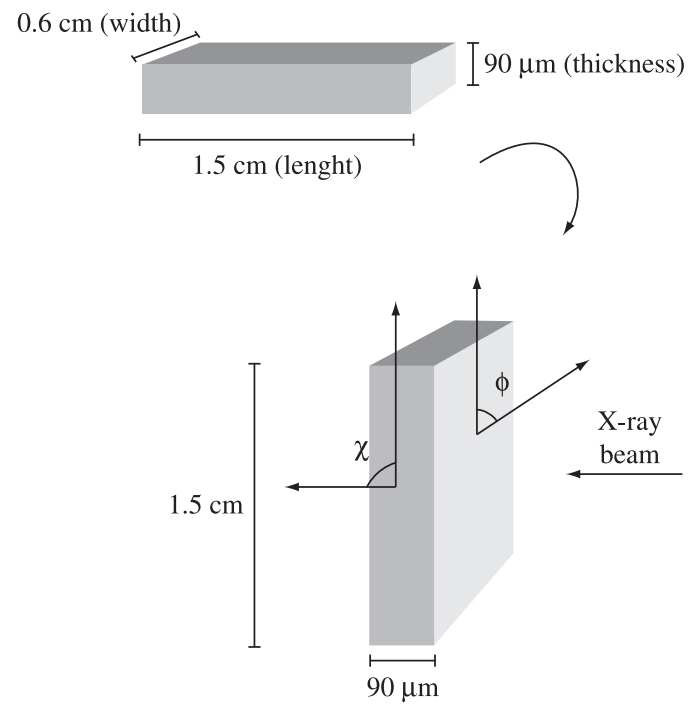

(c)

Figure 1. a) Scheme of the injection molding disk; b) Scheme of the samples used in the WAXD experiments to analyze the type of i-PP phases; and c) to analyze the molecular orientation. 
Table 2. Molding conditions

\begin{tabular}{|c|c|c|c|c|c|c|}
\hline Condition & Sample & $\mathrm{T}_{\mathrm{i}}\left({ }^{\circ} \mathrm{C}\right)$ & $\mathrm{T}_{\mathrm{w}}\left({ }^{\circ} \mathrm{C}\right)$ & $\mathrm{Q}\left(\mathrm{cm}^{3} / \mathrm{s}\right)$ & $\mathrm{P}_{\mathrm{p}}(\mathrm{bar})$ & $t_{p}(s)$ \\
\hline 03 & HPP03; NPP03 & 240 & 90 & 75 & 550 & 5.0 \\
\hline 06 & HPP06; NPP06 & 240 & 55 & 40 & 400 & 12.5 \\
\hline 08 & HPP08; NPP08 & 240 & 30 & 75 & 550 & 5.0 \\
\hline 11 & HPP11; NPP11 & 220 & 30 & 40 & 400 & 12.5 \\
\hline 12 & HPP12; NPP12 & 220 & 55 & 75 & 400 & 12.5 \\
\hline 15 & HPP15; NPP15 & 220 & 55 & 40 & 400 & 12.5 \\
\hline 18 & HPP18; NPP18 & 220 & 55 & 5 & 400 & 12.5 \\
\hline 19 & HPP19; NPP19 & 220 & 90 & 40 & 400 & 12.5 \\
\hline 24 & HPP24; NPP24 & 200 & 55 & 40 & 400 & 12.5 \\
\hline
\end{tabular}

Table 3. Penetration of the X-ray beam along the thickness.

\begin{tabular}{ccc}
\hline $\begin{array}{c}\text { Thickness of the } \\
\text { removed layer }(\mu \mathrm{m})\end{array}$ & $\begin{array}{c}\text { Depth of X-ray } \\
\text { penetration }(\mu \mathrm{m})\end{array}$ & Region \\
\hline 0 (surface) & 885 & $\mathrm{~A}$ \\
$90\left(1^{\text {st }}\right.$ cut $)$ & 975 & $\mathrm{~B}$ \\
$160\left(2^{\text {nd }}\right.$ cut $)$ & 1045 & $\mathrm{C}$ \\
$240\left(3^{\text {rd }}\right.$ cut $)$ & 1125 & $\mathrm{D}$ \\
\hline
\end{tabular}

It is well known that polypropylene under extensional or shear flow results in samples exhibiting bimodal orientation ${ }^{34}$. This distinctive bimodal orientation is unique to isotactic polyproplylene and is attributed to the crystallographic branching of "daughter" lamellae growing epitaxially with their a- and c-axes parallel to the c- and a-axes of the "parent" lamellae respectively ${ }^{35,36}$. Kumaraswamy and coworkers ${ }^{37}$ demonstrated that PP crystallites that presents highly oriented structures, where cross-hatched daughter lamellae appear almost immediately, grows simultaneous and in proportion to its parent lamellae. They also demonstrated that the morphology of the skin consists of parent lamellae that radiate out from threads along the flow direction consistent with the model of Liedauer and coworkers ${ }^{38}$.

Thus, in this work the influence of some injection molding processing conditions on the development of $\alpha$-and $\beta$-phases and on the molecular orientation of two i-PP, one with nucleating agent and the other without, were studied by wide angle X-ray diffraction (WAXD) and pole figures. Therefore, the main proposal of this article was the comprehensive study of the interrelations between the processing conditions, phase contents and PP $\alpha$-phase molecular orientation of injection molded PP resins.

\section{Experimental}

\subsection{Materials}

Two i-PP resins, from Braskem ${ }^{\circledR}$ S.A., Brazil, were used in this work. The first resin, named HPP, was a homopolymer without nucleating agent. The second resin, named NPP, had sodium benzoate as nucleating agent in the concentration up to the critical concentration at which the $\beta$-form content reaches the saturation level $1^{19,20,39}$. Properties of both resins are shown in Table 1 .

\subsection{Injection molding}

The polymers were injection molded in a machine from Arburg Allrounder, model $270 \mathrm{~V}$, with a closing force of $300 \mathrm{kN}$ and screw diameter of $25 \mathrm{~mm}$. The mold was cooled using a unit from HB THERM, model HBW 140. An iron-constantan thermocouple was used to check the mold temperature periodically. The mold cavity had disk geometry, with diameter of $90 \mathrm{~mm}$ and thickness of $2 \mathrm{~mm}$, a sapphire window to optically monitor each injection molded cycle and a pressure transducer, as already described in our previous work ${ }^{40}$. The polymer was injected through the center of the cavity, as shown in Figure 1a.

During the injection molding, the following parameters were changed: injection temperature $\left(\mathrm{T}_{\mathrm{i}}\right)$, mold temperature $\left(\mathrm{T}_{\mathrm{w}}\right)$, injection flow rate $(\mathrm{Q})$, packing pressure $\left(\mathrm{P}_{\mathrm{p}}\right)$ and packing time $\left(\mathrm{t}_{\mathrm{p}}\right)$. The processing window of the polymers was determined after finding a compromise between the polymers properties and the injection molding machine characteristics that guaranteed useful injected articles and reliable optical sensor signals, as already described ${ }^{40}$. Table 2 shows the analyzed molding conditions. These analyzed conditions were chosen based on early study ${ }^{40}$ that shows that the mold temperature and flow rate are the parameters that affected most the kinetics of crystallization of these polymers in this particular disk geometry.

\subsection{Crystalline phase analysis}

To analyze the type of i-PP phases by WAXD, a disk of $1 \mathrm{~cm}$ of diameter and $2 \mathrm{~mm}$ of thickness, at the sapphire window region of the injected sample was cut. The WAXD experiments were done using a Siemens ${ }^{\circledR}$ D5005 equipment, with Ni-filtered $\mathrm{CuK} \alpha$ radiation, between $5^{\circ}$ and $50^{\circ}$, at a rate of $0.05^{\circ} / 3 \mathrm{~s}$. The disks were microtomed to remove layers of 90,160 and $240 \mu \mathrm{m}$ of thickness. After each layer removal, a WAXD run was done on the reminiscent surfaces, designed as $1^{\text {st }}, 2^{\text {nd }}$ and $3^{\text {rd }}$ cuts, respectively, as shown in Figure $1 b$. All X-ray diffractograms were normalized with respect to sample thickness and incident beam intensity.

In order to known the true layer analyzed by X-ray, the penetration of the X-ray beam was calculated using the following equation ${ }^{41}$.

$$
\frac{I}{I_{\text {inc }}}=\exp ^{-\mu \cdot e}=\exp ^{-M A C \rho \cdot e}
$$

where: $I$ is the transmitted intensity, $I_{i n c}$ is the incident intensity, $\mu$ is the polymer absorption coefficient, $e$ is the sample thickness (or penetration depth), MAC is the weight absorption coefficient and $\rho$ is the polymer density. The parameter MAC was calculated from reference 30 , and it was found to be 4.001 .

\subsection{Molecular orientation by WAXD pole figures}

To measure the molecular orientation of the i-PP, samples of $15 \mathrm{~mm}$ length, $6 \mathrm{~mm}$ width and $90 \mu \mathrm{m}$ thickness were cut at the sapphire window region, as shown in Figure 1c.

The molecular orientation of the samples was evaluated by the spatial distribution of the diffracted intensity of the (110) and (040) crystallographic planes, which reflect at $2 \theta=14.1$ and $16.8^{\circ}$, respectively. 


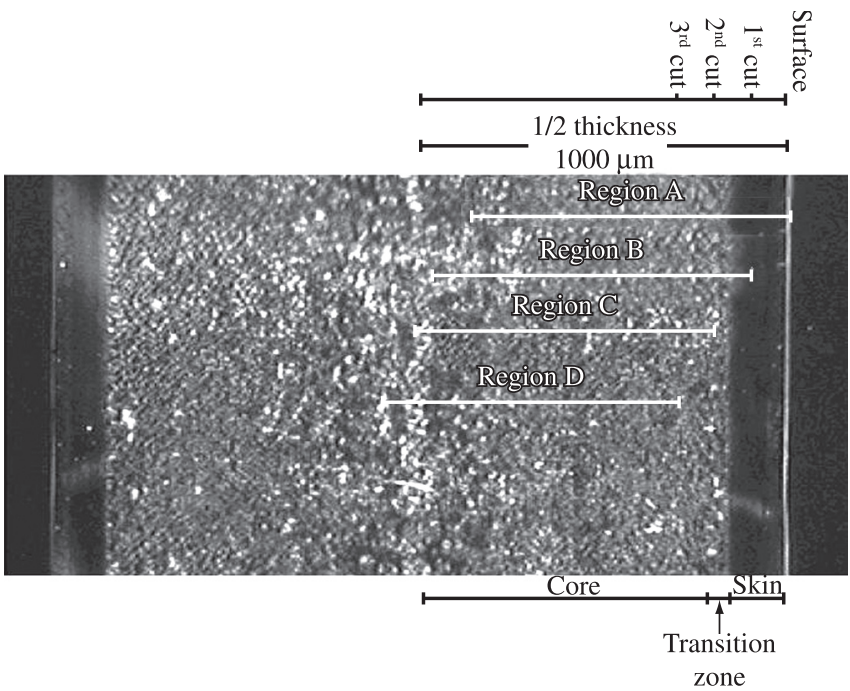

Figure 2. Regions where the WAXD analyses were done.

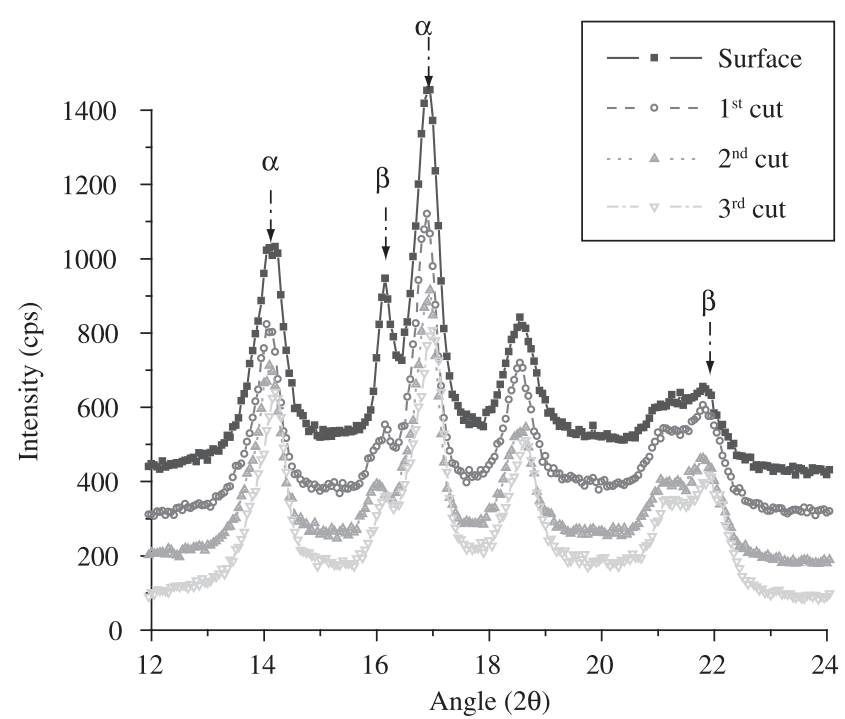

(a)

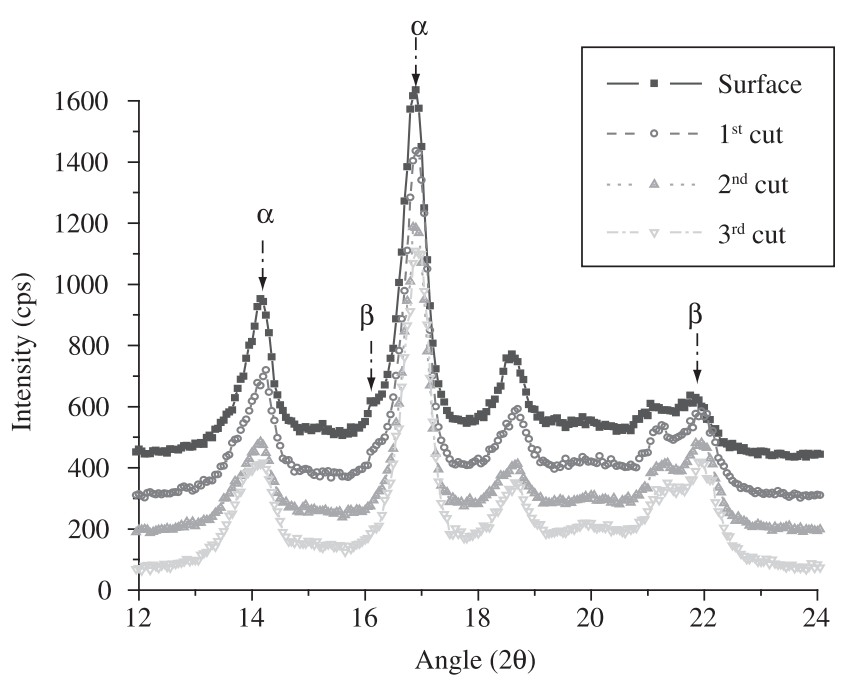

(b)

Figure 3. Diffractograms along the thickness of samples a) HPP15 and b) NPP15.
Table 4. Diffraction peaks of the i-PP samples s $^{25,26}$

\begin{tabular}{ccc}
\hline $2 \theta\left(^{\circ}\right)$ & $\begin{array}{c}\text { Crystalline plane } \\
(\mathrm{hkl})\end{array}$ & i-PP phase \\
\hline 14.1 & $(110)$ & $\alpha$ \\
16.1 & $(300)$ & $\beta$ \\
16.8 & $(040)$ & $\alpha$ \\
18.5 & $(130)$ & $\alpha$ \\
21.2 & $(111)$ & $\alpha$ \\
21.8 & $(301)$ & $\beta$ \\
25.5 & $(060)$ & $\alpha$ \\
\hline
\end{tabular}

The pole figures were obtained using a high-resolution X-ray diffraction beamline, XRD2, of the Brazilian Synchrotron Light Laboratory (LNLS). The beam energy was tuned to $8049.9 \mathrm{eV}$. The incident beam was collimated by a $3 \times 1.6 \mathrm{~mm}$ diffraction slit coupled with a $0.5 \mathrm{~mm}$ slit located just before the detector. Data were obtained using a six-circle diffractometer with a cradle by rotating the sample at scanning angles of $0 \leq \phi \leq 360^{\circ}$ and tilting the sample between $0^{\circ} \leq \chi \leq 90^{\circ}$; these angles are shown in Figure 1c. An angle step of $5^{\circ}$ for $\phi$ and $\chi$ was used during the measurements. Exposition times were adjusted in agreement with intensities. Correction background, absorption effects and the connection of both experimental methods were performed by the $\mathrm{Polo}^{\circledR} 2003$ software before plotting the pole figures.

From the intensities of the (110) and (040) crystalline planes, the macromolecules $j$-axis orientations along the radial or flow direction (RD), the transverse direction (TD) and the normal direction (ND) were calculated; the average square cosine of $\phi_{j}$ (where $\phi_{j}$ is the angle between the $\mathrm{j}$-axis and the chosen direction) or $\left\langle\cos ^{2} \phi_{\mathrm{j}, \mathrm{RD}}\right\rangle$, $<\cos ^{2} \phi_{\mathrm{j}, \mathrm{TD}}>$ and $<\cos ^{2} \phi_{\mathrm{j}, \mathrm{ND}}>$ were obtained. Finally, the three orientation factors $(f)$ were obtained using the following equations:

$$
\begin{gathered}
f_{j, D}=\frac{3<\cos ^{2} \varphi_{j, D}>-1}{2} \\
f_{a, R D}+f_{b, T D}+f_{c, N D}=1
\end{gathered}
$$

where: $j$ corresponds to the crystallographic axes $(j=\mathrm{a}, \mathrm{b}$ or $\mathrm{c})$ and $D$ is the reference direction $(D=\mathrm{RD}, \mathrm{TD}$ or ND). $\mathrm{f}=1.0$ represents parallel orientation along the reference axis; $f=-0.5$, perpendicular orientation with respect to the reference axis, and $f=0$ represents an isotropic sample ${ }^{30,41}$.

\section{Results and Discussions}

\subsection{Crystalline phase analyses}

From Equation 1 using $2 \theta=16.1^{\circ}$ (crystallographic plane of i-PP $\beta$ phase), the penetration depth was found to be $885 \mu \mathrm{m}$. Table 3 shows the calculated depth of X-ray penetration after the removal of each layer while Figure 2 shows the regions of penetration of each WAXD analyses after layer removal.

It can be observed, therefore, that when the first surface was analyzed the diffractograms were a result of the X-rays interaction with the whole skin and transition zones and part of the core; when the $1^{\text {st }}$ cut was analyzed, the diffractograms were result of the X-rays interaction with part of the skin zone, the whole transition zone and part of the core, and so on. Some typical diffractograms of these surfaces are shown in Figure 3. It can be observed that all samples had $\alpha$ - and $\beta$-phases, as expected since the shear and temperature gradients can induce the formation of $\alpha$-phase and/or even $\beta$-phase 


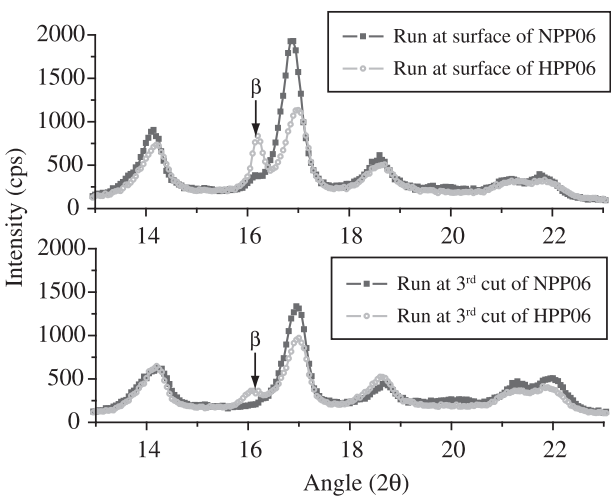

(a)

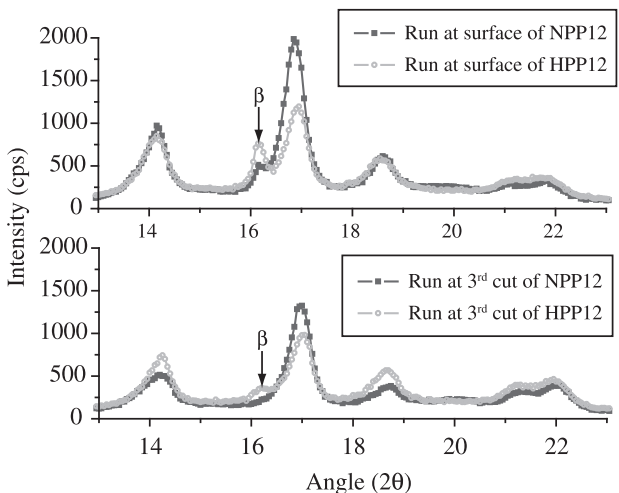

(c)

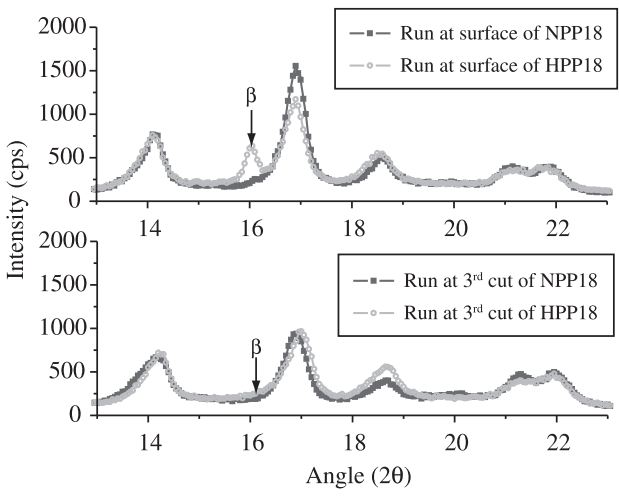

(e)

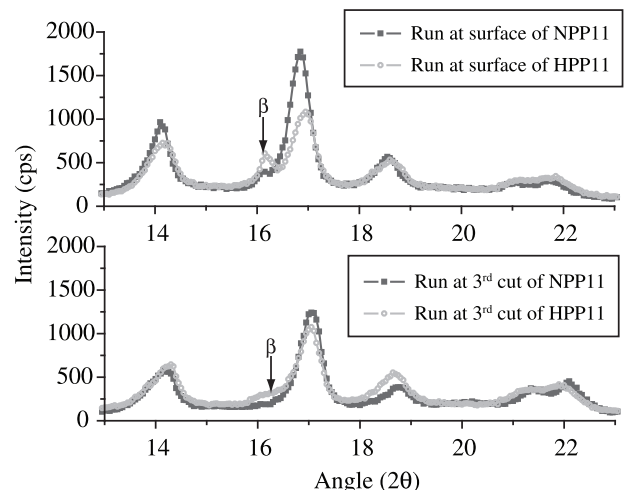

(b)

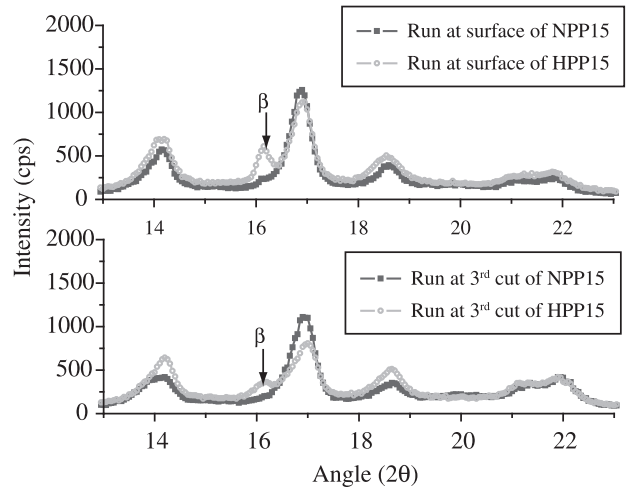

(d)

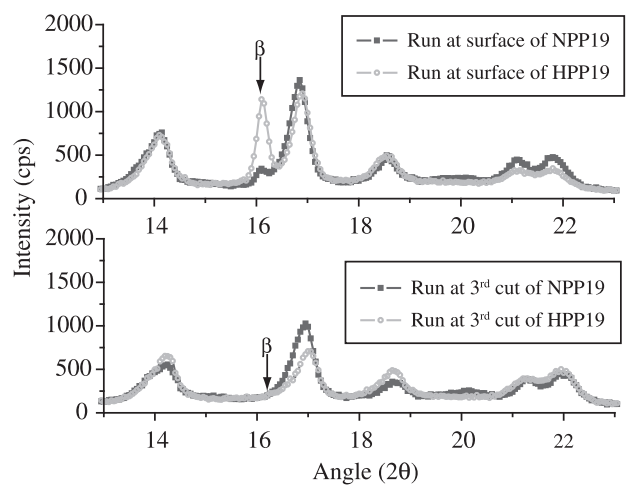

(f)

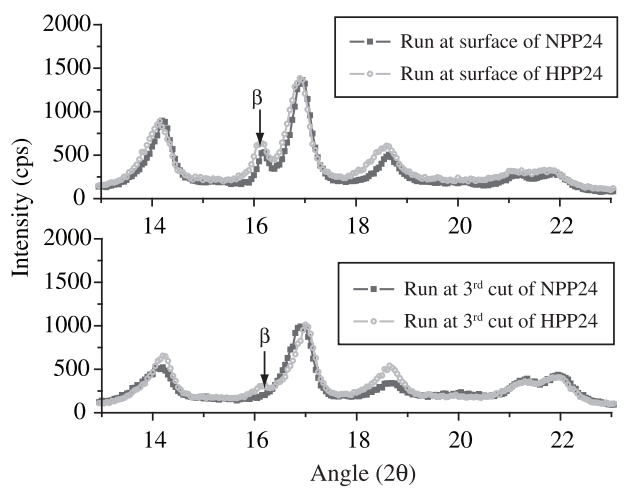

(g)

Figure 4. Diffractograms along the thickness of samples a) HPP06 and NPP06; b) HPP11 and NPP11; c) HPP12 and NPP12; d) HPP15 and NPP15; e) HPP18 and NPP18; f) HPP19 and NPP19; and g) HPP24 and NPP24. 
during the molding process. However, it is well known that the $\alpha$-phase is a dominant crystalline modification ${ }^{42}$. The characteristics diffraction peaks for these phases are shown in Table 4. The $\alpha$ - and $\beta$-phases could become dominant when some special agents (as $\alpha$ - or $\beta$-nucleants) are added, in our case should be emphasized that the sodium benzoate nucleating agent present in the used NPP resin, is a conventional $\alpha$-form nucleator and can also induce $\beta$-form iPP under certain conditions, been than less effective ${ }^{17}$. Crystallization in a temperature gradient or in sheared or strained melt encourages the development of the $\beta$-phase in commercial iPP ${ }^{42}$.

The amount of each phase along the thickness of the injected samples was analyzed using three diffraction peaks [(110) and (040) planes for the $\alpha$-phase and (300) plane for the $\beta$-phase]. The $\alpha$-phase planes were chosen because they were the most intense, while the $\beta$-phase plane was chosen because they was the only plane of pure the $\beta$-phase that appeared in the studied $2 \theta$ range. The (301) $\beta$-peak is overlapped with (111) $\alpha$ - peak, these reflections appearing at angle $2 \theta=21.3$ and $21.8^{\circ}$ respectively, so close. It should be emphasized that WAXD profiles are known to be affected by crystal orientation. In general, if the $a-, b-$ or c-axes of the crystals are aligned perpendicular to the surface of the injected sample, the reflection intensity of the $(h 00),(0 k 0)$ or $(00 l)$ planes are strong in the diffraction when the X-ray beam is parallel to the flow direction.

From Figure 3, it can be observed that the intensity of the (300) plane ( $\beta$-phase) decreased significantly from the surface to the core ( $3^{\text {rd }}$ cut $)$ of the samples for both materials. On the other hand, the peaks corresponding to the $\alpha$-phase remained constant along the thickness of the samples.

The same behavior was observed at all injection molding conditions for both materials, as shown in Figure 4; that is, the $\alpha$-phase was present in all layers of the injected samples, while the $\beta$-phase decreased from the surface to the core. The formation of the $\beta$-phase, among other factors, is dependent of the shear level imposed to the polymer during the injection molding; it is known ${ }^{1,22}$ that its amount decreases with the decrease in shear rate, as confirmed by our results. Table 5 shows the measured intensities of the (300) peak at all studied conditions.

It is also observed that in the HPP the amount of $\beta$-phase was higher than in the NPP, which is probably related to the NPPs crystallization kinetics. NPP has a faster crystallization than the HPP; therefore, the crystallization and solidification of the layers in the NPP occurred quicker than in the HPP which made the NPP macromolecules to be submitted to shear rates for shorter periods of time than the HPP macromolecules.

Another confirmation of the observation that the formation of the $\beta$-phase is triggered by the level and duration of the shear rate can be obtained if the mold temperature is changed ${ }^{42}$; for example, if conditions 11, 15 and 19 are analyzed, it can be observed that the amount of $\beta$-phase at the surface increases with the increase in mold temperature. At the mold walls, as the mold temperature increases, the crystallization or solidification time also increases; therefore, the macromolecules chains will be sheared during longer times as the mold temperature increases and higher amounts of $\beta$-phase will be formed. On the other hand, at the core, because the shear rates are zero, no $\beta$-phase will be produced, independent of the mold temperature. The low $\beta$-phase at the core region in the NPP samples is probably due to the nucleating agent effect.

\subsection{Molecular orientation by pole figures}

Analyzing all the diffractograms, it was also observed that in this study two processing parameters which most influence the molecular orientation were the mold temperature $\left(\mathrm{T}_{\mathrm{w}}\right)$ and the injection flow rate $(\mathrm{Q})$. In other words, crystallization temperature and shear rate are most influential parameters on molecular orientation. Many studies have been extended to other aspects such chain length (which is related to the relaxation time), entanglements, and interfacial stress. In this work, in order to investigate the influence of $\mathrm{T}_{\mathrm{w}}$ and $\mathrm{Q}$ on the orientation of the HPP and NPP samples, the molecular orientation of samples injected at conditions $03,08,12,15$ and 18 was evaluated. To shorten the amount of experimental work, measurements were done only on the sample surface (skin layer). Details about the influence of processing parameters on the level of molecular orientation along the samples thickness of injection molded PP has already been discussed in the literature $24,34,43,44$.

The pole figures were plotted in a bi-dimensional (2D) projection with the RD and TD in the plane and the ND perpendicular to the RD/TD plane. The pole densities were indicated inside the pole figures near the isolines. Figure 5 shows the obtained WAXD pole figures of the (110) and (040) reflections of the $\alpha$-phase of all nonnucleated samples. The results of the nucleated samples are shown in Figure 6. By comparison between Figure 5 and Figure 6 it can be seen that the pole figures for all samples have similar shape, but with different pole density.

In all samples there is a strong characteristic of the c-axis parallel to $\mathrm{RD}$ and the $\mathrm{b}$-axis perpendicular to RD. In the (110) plane pole figures, two maxima are observed. One indicates that a major fraction of the (110) planes has its normal parallel to the ND/TD plane, that is, perpendicular to the flow direction, which corresponds to a c-axis orientation in the flow direction. The other maximum indicates that a significant amount (but minor fraction) of (110) planes has its normal parallel to the flow direction which corresponds to named $\mathrm{a}^{*}$-axis orientation in the flow direction ${ }^{2,36,37}$. In this case, the $\mathrm{a}^{*}$-axis is oriented parallel to the $\mathrm{RD}$ and the c-axis is preferentially oriented in the RD/TD plane.

Table 5. Intensity of the (300) peak of all the studied conditions.

\begin{tabular}{|c|c|c|c|c|c|c|c|}
\hline \multicolumn{8}{|c|}{ Intensity of the (300) peak at the surface (cps) } \\
\hline Condition & 06 & 11 & 12 & 15 & 18 & 19 & 24 \\
\hline HPP & 626.27 & 401.79 & 543.43 & 399.58 & 432.45 & 979.16 & 461.03 \\
\hline NPP & 641.21 & 110.27 & 302.98 & 100.00 & 96.49 & 184.73 & 357.62 \\
\hline \multicolumn{8}{|c|}{ Intensity of the (300) peak at $3^{\text {rd }}$ cut $(\mathrm{cps})$} \\
\hline Condition & 06 & 11 & 12 & 15 & 18 & 19 & 24 \\
\hline HPP & 193.71 & 0 & 154.49 & 112.54 & 0 & 0 & 80.08 \\
\hline NPP & 0 & 0.40 & 0.94 & 0 & 0 & 0 & 0 \\
\hline
\end{tabular}


(a)

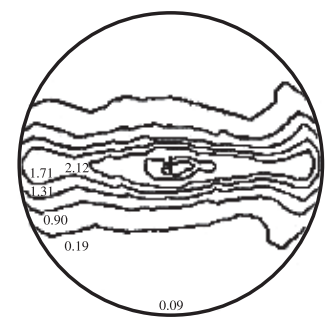

(b)

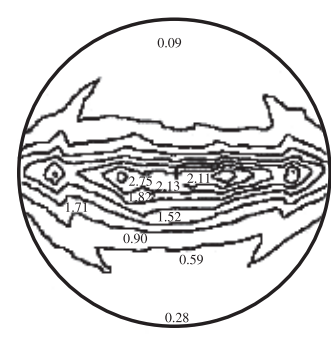

(c)

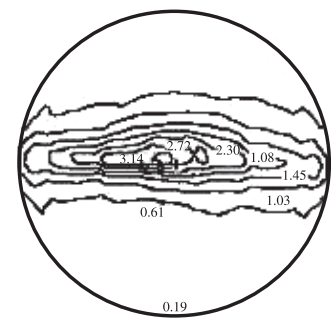

(d)

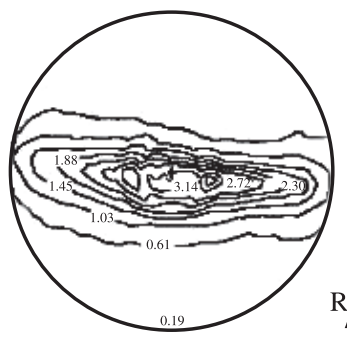

(e)

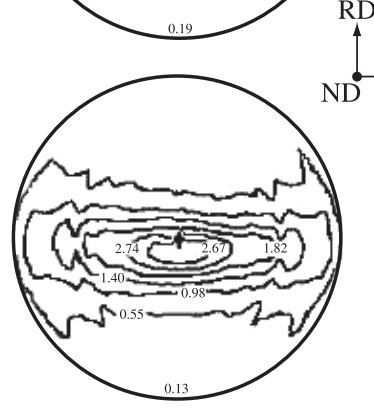

(110)
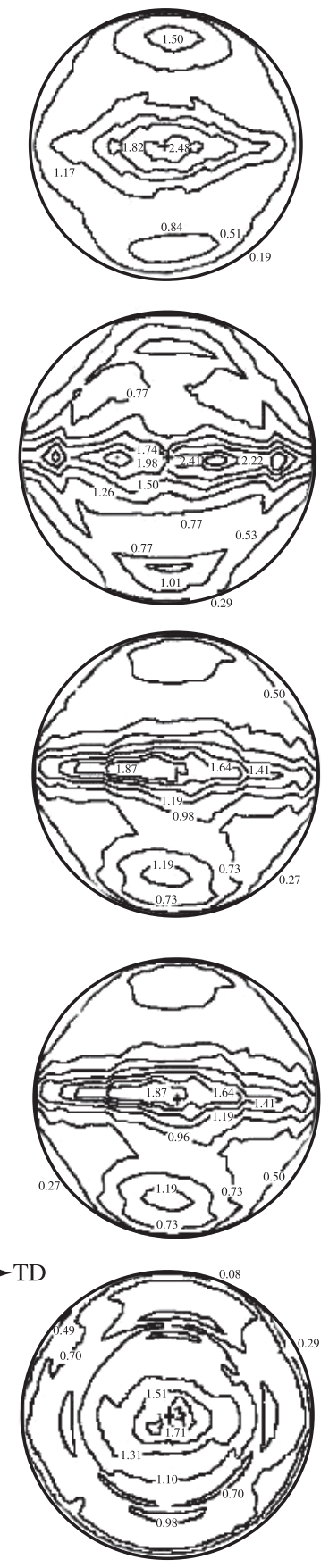

Figure 5. 2D projection of the WAXD pole figures for the (040) and (110) planes of the (a) HPP03 (b) HPP08 (c) HPP12 (d) HPP15 (e) HPP18 samples.

However, from the pole densities it is possible to observe that the c-axis orientation of the lamellae is higher in the flow direction than in the $\mathrm{a}^{*}$ axis orientation. This specific bimodal crystalline orientation has been discussed in the literature ${ }^{31,32,44}$. Mendoza and coworkers ${ }^{24}$ described that the two components ( $\mathrm{a}^{*}$-axis component and c-axis component) have a large orientation distribution, the $\mathrm{a}^{*}$-axis lamellae could nucleate locally on the c-axis lamellae which have the same crystallographic b-axis.

The molecular orientation factors of the i-PP b- and c-axis were calculated along all three directions (RD, TD and ND) from the pole

(040)

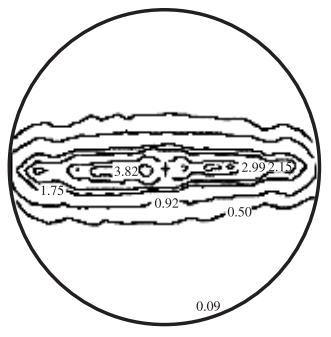

(b)

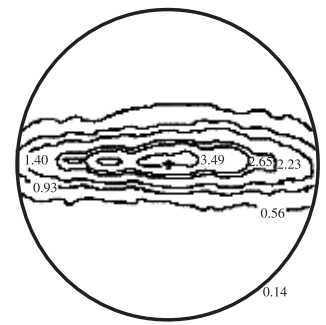

(c)

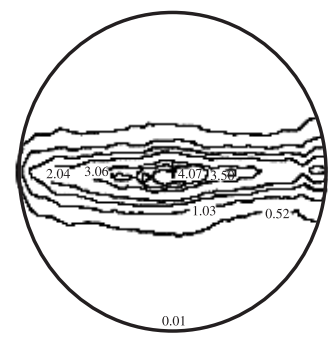

(d)
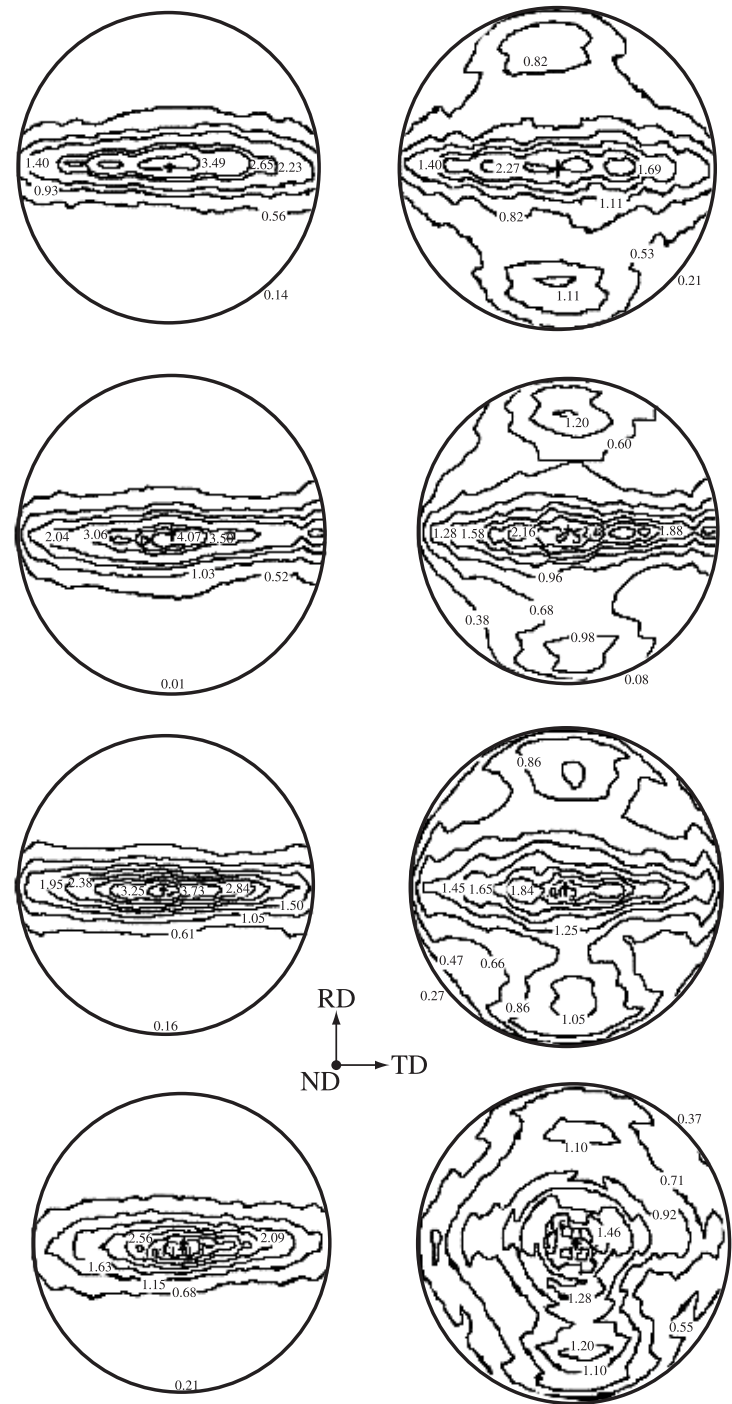

(e)

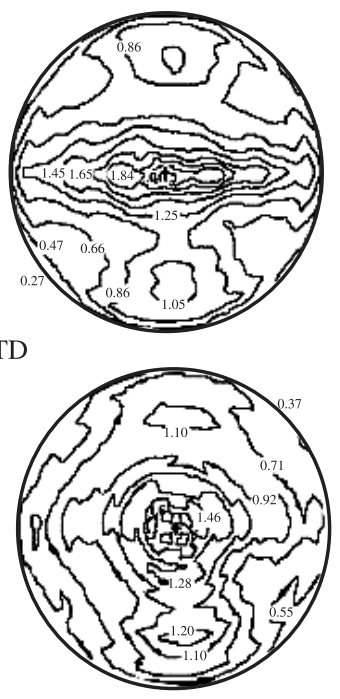

Figure 6. 2D projection of the WAXD pole figures for the (040) and (110) planes of the (a) NPP03 (b) NPP08 (c) NPP12 (d) NPP15 (e) NPP18 samples.

figures and are shown in Table 6. The orientation of the crystalline phase was moderate for all samples. Regarding the influence of some processing parameter, it can be observed that:

\subsubsection{Influence of the polymer}

For both polymers, the orientation of the macromolecules c-axis was higher along RD than along TD. The b-axis was oriented to the thickness direction, ND. It is known that shear rates $\gamma$ are less efficient on promoting macromolecular orientation than elongational rates 
Table 6. Calculated molecular orientation factors of the b- and c-axes along the radial (RD), transverse (TD) and normal (ND) directions.

\begin{tabular}{cccccccccccccc}
\hline \multirow{2}{*}{ Condition } & \multicolumn{2}{c}{$f \mathrm{c}, \mathrm{RD}$} & \multicolumn{2}{c}{$f \mathrm{c}, \mathrm{TD}$} & \multicolumn{2}{c}{$f \mathrm{c}$, ND } & \multicolumn{2}{c}{$f \mathrm{~b}, \mathrm{RD}$} & \multicolumn{2}{c}{$f \mathrm{~b}$, TD } & \multicolumn{1}{c}{$f \mathrm{~b}, \mathrm{ND}$} \\
\cline { 2 - 13 } & HPP & NPP & HPP & NPP & HPP & NPP & HPP & NPP & HPP & NPP & HPP & NPP \\
\hline 03 & 0.34 & 0.41 & 0.08 & 0.04 & -0.45 & -0.45 & -0.28 & -0.32 & 0.02 & 0.02 & 0.27 & 0.30 \\
08 & 0.34 & 0.40 & 0.01 & 0.05 & -0.35 & -0.45 & -0.23 & -0.29 & 0.01 & -0.01 & 0.22 & 0.30 \\
12 & 0.35 & 0.43 & 0.07 & 0.07 & -0.42 & -0.50 & -0.10 & -0.32 & -0.06 & -0.01 & 0.15 & 0.33 \\
15 & 0.35 & 0.39 & 0.08 & 0.05 & -0.43 & -0.44 & -0.09 & -0.32 & -0.06 & 0.01 & 0.16 & 0.30 \\
18 & 0.28 & 0.32 & 0.07 & 0.12 & -0.36 & -0.44 & -0.04 & -0.28 & -0.07 & -0.02 & 0.11 & 0.30 \\
\hline
\end{tabular}
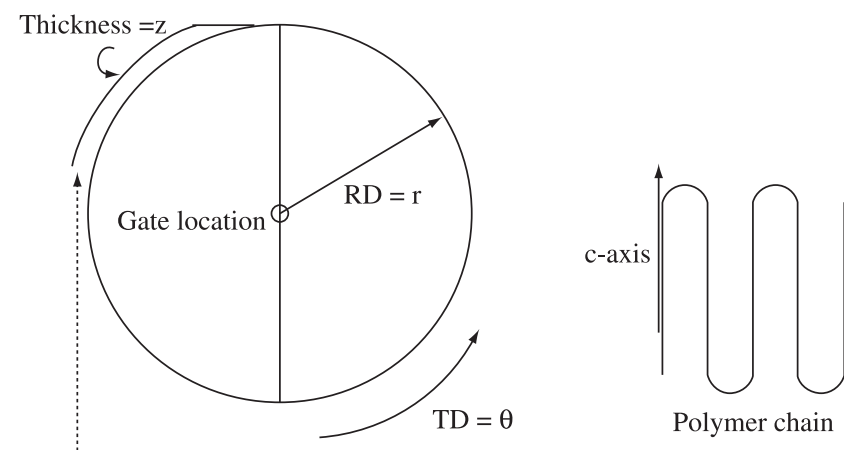

(a)

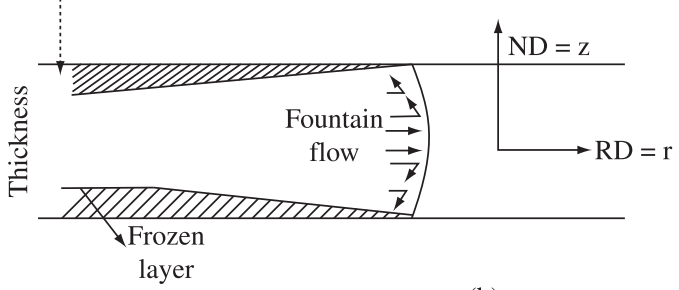

(b)

$$
\begin{aligned}
& \dot{\gamma}_{r z}=\frac{\partial V_{r}}{\partial z}+\frac{\partial V_{z}}{\partial r} \\
& \dot{\gamma}_{\theta r}=r \frac{\partial}{\partial r}\left(\frac{V_{\theta}}{r}\right)+\frac{1}{r} \frac{\partial V_{r}}{\partial \theta} \\
& \dot{\gamma}_{z \theta}=\frac{\partial V_{\theta}}{\partial z}+\frac{1}{r} \frac{\partial V_{z}}{\partial \theta}
\end{aligned}
$$

$$
\begin{aligned}
& \dot{\varepsilon}_{r r}=2 \frac{\partial V_{r}}{\partial r} \\
& \dot{\varepsilon}_{z z}=2 \frac{\partial V_{z}}{\partial z} \\
& \dot{\varepsilon}_{\theta \theta}=2\left(\frac{1}{r} \frac{\partial V_{\theta}}{\partial \theta}+\frac{V_{r}}{r}\right)
\end{aligned}
$$

Figure 7. a) Scheme of the flow along the three main directions; and b) Components of the deformation rates, where $\mathrm{Vr}, \mathrm{V} \theta$ and $\mathrm{Vz}$ are the components of the velocity in the $\mathrm{r}, \theta$ and $\mathrm{z}$ directions, respectively.

$\dot{\varepsilon}^{45}$. Therefore, we will focus mainly on the elongational deformation acting on the disk, as shown in Figure 7. If it is assumed that $V_{\mathrm{z}}=0$ (which will make $f_{\mathrm{C}, \mathrm{ND}} \approx 0$ ), then the elongation rates acting on the macromolecules will only be $\dot{\varepsilon}_{\mathrm{rr}}$ and $\dot{\varepsilon}_{\theta \theta} \cdot \dot{\varepsilon}_{\mathrm{rr}} \neq 0$, because $V_{\mathrm{r}}$ will change with $r$ (the flow area perpendicular to $r$ is increasing with $r$ and consequently $V_{\mathrm{r}}$ is decreasing with $r$ ) while $\dot{\varepsilon}_{\theta \theta} \neq 0$ due to the accelerating "fountain flow". Both rates can be calculated from:

$$
\dot{\varepsilon}_{r r}=2 \frac{\Delta V_{r}}{\Delta r} \text { or } \dot{\varepsilon}_{\theta \theta}=2 \frac{\Delta V_{\theta}}{\Delta \theta} ;
$$

from this geometry it can be observed that $\Delta V_{\mathrm{r}}>\Delta V_{\theta}$ and $\dot{\varepsilon}_{\mathrm{rr}}>\dot{\varepsilon}_{\theta \theta}$, thus the orientation along $\mathrm{RD} \equiv \mathrm{r}$ will be higher than along $\mathrm{TD} \equiv \theta$, as observed.
The orientation of the c-axis along RD and b-axis along ND of the NPP samples was considerably higher than of the HPP samples; the NPP due to its faster crystallization kinetics and consequently its faster solidification; this solidification will cause a decrease in the flow area perpendicular to $r$ and consequently an increase in the velocity and an increase in orientation levels.

\subsubsection{Influence of mold temperature}

It can be observed that, in general, as the mold temperature increased, the characteristic molecular orientation of PP, with c-axis along RD and b-axis along ND, decreased. With the increase of mold temperature, the difference between injection and mold temperature decreased, the cooling was slower and the macromolecules relaxed faster, which resulted in low orientation degree.

\subsubsection{Influence of the injection flow rate}

With the increase of the injection flow rate, an increase of the c-axis molecular orientation of the samples along RD was observed. There was also an increase of the b-axis orientation along ND with the increase in flow rate. As the flow rate increased, the flow velocities increased increasing the distinctive molecular orientation of PP. These results agree with earlier results ${ }^{22}$.

\section{Conclusions}

WAXD analyses and WAXD pole figures of injection molded disks of two i-PP resins, HPP and NPP, as a function of different processing conditions showed that:

- In both resins, independently of the injection molding conditions, the $\alpha$-phase was present in all regions along the thickness. On the other hand, the amount of $\beta$-phase was high in the HPP resin at all molding conditions but low in the NPP resin; this phase decreased along the thickness, decreasing with the decrease in shear rate. Therefore, the formation of the $\beta$-phase is triggered by the level and duration of the shear rate;

- For both polymers, the orientation of the macromolecules c-axis was higher along RD than along TD. The b-axis was oriented to the thickness direction, ND. The orientation of the c-axis along RD and b-axis along ND of the NPP samples was considerably higher than of the HPP samples, due to the NPP faster crystallization kinetics; and

- For both polymers, the most influential processing parameters on the molecular orientation were the mold temperature and flow rate; it was observed that, as the mold temperature increased, the characteristic molecular orientation of PP decreased, due to the decrease of the cooling rate and the increase of the macromolecules relaxation process, and as the injection flow rate increased, an increase of the distinctive orientation of PP was observed due to the increase of the flow velocities. 


\section{Acknowledgements}

The authors are grateful to FAPESP for the financial aid, to Braskem S.A. for the polymers donation and to J. Marini and M. $\mathrm{K}$. Bertolino for the help with the drawings. This work was also supported by the LNLS under proposal D10A-XRD2-4621. Special thanks are given to Dr. G. Kellerman for the helpful WAXD experimental discussions.

\section{References}

1. Farah M and Bretas RES. Characterization of i-PP Shear-Induced Crystallization Layers Developed in a Slit Die. Journal of Applied Polymer Science. 2004; 91(6):3528-3541.

2. Pantani R, Coccorullo I, Speranza V and Titomanlio G. Modeling of morphology evolution in the injection molding process of thermoplastic polymers. Progress in Polymer Science. 2005; 30(12):1185-1222.

3. Pantani R, Coccorullo I, Speranza V and Titomanlio G. Morphology evolution during injection molding: Effect of packing pressure. Polymer. 2007; 48(9):2778-2790.

4. Viana JC. Development of the skin layer in injection moulding: phenomenological model. Polymer. 2004; 45(3):993-1005.

5. Viana JC, Cunha AM and Billon N. The Thermomechanical environment and the microestruture of an injection moulded polypropylene copolymer. Polymer. 2002; 43(15):4185-4196.

6. Favaro MM. Monitoramento da cristalização de resinas de polipropileno durante a moldagem porinjeção. [Dissertação de Mestrado]. São Carlos: Universidade de São Carlos; 2005.

7. Zhu PW and Edward G. Morphological distribution of injection-moulded isotactic polypropylene: a study of synchrotron small angle X-ray scattering. Polymer. 2004; 45(8):2603-2613.

8. Pöstch G and Michaeli W. In injection molding: an introduction. New York: Hanser; 1995.

9. Rosato DV and Rosato DV. In injection molding handbook. New York: Van Nostrand Reinhold; 1986

10. Yu Y and White JL. Structure Development in Injection Molding of Isotactic Polyproylene, its Blends, Compounds and Dynamic Vulcanizates. International Polymer Processing. 2003; 18(4):388-397.

11. Choi D and White JL. Comparison of Structure development in Injection Molding of Isotactic and Syndiotactic Polypropylenes. Polymer Engineering and Science. 2002; 42(8):1642-1656.

12. Varga JJ. Supermolecular structure of isotactic polypropylene. Journal of Materials Science. 1992; 27(10):2557-2579.

13. Karger KJ. In polypropylene: an A-Z reference. Dordrecht: Kluwer Academic Publishers; 1998

14. Kumaraswamy G, Verma RK, Kornfield JA and Hsiao BS. ShearEnhanced Crystallization in Isotactic Polypropylene. In-Situ Synchrotron SAXS and WAXD. Macromolecules. 2004; 37(24):9005-9017.

15. Rajesh H, Somani LY and Hsiao BS. Effects of high molecular weight species on shear-induced orientation and crystallization of isotactic polypropylene. Polymer. 2006; 47(15):5657-5668

16. Scudla J, Eichhorn KJ, Raab M, Schmidt P, Jehnichen D and Haussler L. The effect of specific nucleation on molecular and supermolecular orientation in isotactic polypropylene. Macromolecular Symposia. 2002; 184(1):371-387.

17. Dong M, Guo Z, Su Z and Yu JJ. Study of the crystallization behaviors of isotactic polypropylene with sodium benzoate as a specific versatile nucleating agent. Journal of Polymer Science: Part B Polymer Physics. 2008; 46(12):1183-1192.

18. Cermak R, Obadal M, Ponizil P, Polaskova M, Stoklasa K and Lengalova A. Injection-moulded $\alpha$ - and $\beta$-polypropylenes: I. Structure vs. processing parameters. European Polymer Journal. 2005; 41(8):1838-1845.

19. Obadal M, Cermak R, Baran N, Stoklasa K and Simonik J. Impact Strength of $\beta$-Nucleated Polypropylene. International Polymer Processing. 2004; 19(1):35-39.
20. Obadal M, Cermak R, Habrova V, Stoklasa K and Simonık J. Tensile and Flexural Properties of $\beta$-Nucleated Polypropylenes. International Polymer Processing. 2004; 19(1):308-312.

21. Varga J, Breining A and Ehrenstein GW. Injection Moulding of a Commercial $\beta$-Nucleated Polypropylene. International Polymer Processing. 1999; 14(4):358-364.

22. Almeida AM, Branciforti MC and Bretas RES. Avaliação da orientação molecular de moldados de polipropileno utilizando figuras de pólo obtidas por difração de raios X. Polímeros: Ciência e Tecnologia. 2007; 17(1):28-36.

23. Zhu PW, Phillips A, Tung J and Edward G. Orientation distribution of sheared isotactic polypropylene plates through thickness in the presence of sodium benzoate. Journal of Applied Physics. 2005; 97(10):104908.

24. Mendoza R, Régnier G, Seiler W and Lebrun JL. Spatial distribution of molecular orientation in injection molded iPP: influence of processing conditions. Polymer. 2003; 44(11):3363-3373.

25. Aurrekoetxea J, Sarrionandia MA, Urrutibeascoa I and Maspoch ML. Effects of injection moulding induced morphology on the fracture behaviour of virgin and recycled polypropylene. Polymer 2003;44(22):6959-6964.

26. Ward IM. In structure and properties of oriented polymers. London: Applied Science Publishers; 1975

27. Boger A, Heise B, Troll C, Marti O and Rieger B. Orientation of the $\alpha$ - and $\gamma$-modification of elastic polypropylene at uniaxial stretching. European Polymer Journal. 2007; 43(8):3573-3586.

28. Scudla J, Raab M, Eichhorn KJ and Strachota A. Formation and transformation of hierarchical structure of -nucleated polypropylene characterized by X-ray diffraction, differential scanning calorimetry and scanning electron microscopy. Polymer. 2003; 44(16):4655-4664

29. Kech A, Ludwig HC, Möginger B, Eyerer P and Christiansen JC. Mechanical Properties of Isotactic Polypropylene with Oriented and Cross-hatched Lamellae Structure. International Polymer Processing. 2000; 15(2):202-207

30. Wilchinsky ZW. On Crystal Orientation in Polycrystalline Materials. Journal of Applied Physics. 1959; 30(5):792-803.

31. Fujiyama $M$ and Wakino T. Structures and properties of injection moldings of crystallization nucleator-added polypropylenes. I. Structureproperty relationships. Journal of Applied Polymer Science. 1991; 42(10):2739-2740

32. Fujiyama $\mathrm{M}$ and Wakino T. Crystal orientation in injection molding of talc-filled polypropylene. Journal of Applied Polymer Science. 1991; 42(1):9-20.

33. Mendoza R, Régnier G, Seiler W and Lebrun JL. Spatial distribution of molecular orientation in injection molded iPP: influence of processing conditions. Polymer 2003; 44(11):3363-3373.

34. Clark ES and Spruiell JE. Unlimited flex life in the molded-in hinge in polypropylene: a structural hypothesis. Polymer Engineering and Science. 1976; 16(3):176-181

35. Lovinger AJ. Microstructure and unit-cell orientation in $\mathbf{\alpha}$-polypropylene. Journal of Polymer Science: Part B Polymer Physics. 1983; 21(1):97-105.

36. Basset DC and Olley RH. On the lamellar morphology of isotactic polypropylene spherulites. Polymer. 1984; 25(7):935-943.

37. Kumaraswamy G, Verma RK, Issaian AM, Wang P, Kornfield JA, Yeh F et al. Shear-enhanced crystallization in isotactic polypropylene. Polymer. 2000; 41(25):8931-8940. (part 2, Analysis of the formation of the oriented "skin").

38. Liedauer S, Eder G, Janeschitz-Kriegl H, Jerschow P, Geymayer W and Ingolic E. On the Kinetics of Shear Induced Crystallization in Polypropylene. International Polymer Processing. 1993; 8(3):236-244.

39. Kotek J, Raab M, Baldrian J and Grellmann WJ. The effect of specific $\beta$-nucleation on morphology and mechanical behavior of isotactic polypropylene. Journal of Applied Polymer Science. 2002; 85(6):1174-1184. 
40. Favaro MM, Marinelli AL, Farah M and Bretas RES. Optical monitoring of polypropylene crystallization during injection molding. Polymer Engineering and Science. 2008; 48(2):257-266.

41. Alexander LE. In X-ray diffraction methods in polymer science. New York: John Wiley and Sons; 1969.

42. Varga JJ. $\beta$-modification of isotactic polypropylene: preparation, structure, processing, properties and application. Journal of Macromolecular Science: Part B Physics. 2002; 41(4-6):1121-1171.
43. Tadmor Z. Molecular orientation in injection molding. Journal of Applied Polymer Science. 1974; 18(6):1753-1772.

44. Isayev AI. Orientation development in the injection molding of amorphous polymers. Polymer Engineering and Science. 1983; 23(5):271-284.

45. Silva LB, Ueki M, Farah M, Barroso VC, Maia JM and Bretas RES. Transient shear and elongational behavior of blends of PET with a LCP. Rheologica Acta. 2006; 45(3):268-280. 